\title{
BORGES Y LOS PROBLEMAS FILOSÓFICOS ${ }^{1}$ \\ BORGES AND THE PHILOSOPHICAL PROBLEMS
}

\author{
Jorge Gregorio Posada \\ Docente Programa de Filosofía, Universidad del Quindío
}

Fecha de recibido: Febrero 3 de 2010

Fecha de aceptado: Junio 9 de 2010

Correspondencia: Programa de Filosofía, Universidad del Quindío Av. Bolivar calle 12 norte Armenia Quindio. Correo electrónico: gposada@uniquindio.edu.co

\section{RESUMEN}

El siguiente artículo intenta mostrar cómo los argumentos de algunos cuentos de Jorge Luis Borges siguen la estructura de los problemas filosóficos. Se describen los problemas filosóficos como inconsistencias en los patrones de creencias que dan una imagen básica sobre el modo de ser de la naturaleza y el hombre. Así, "Las tres versiones de Judas" y "Las ruinas circulares", del libro Ficciones, recrean los problemas filosóficos del determinismo y el escepticismo, respectivamente. El Primero muestra que no podemos tener una imagen consistente de nuestra capacidad de autodeterminación cuando asumimos que la historia y el comportamiento natural no son el resultado de una serie consecutiva de fenómenos antojadizos; el segundo, recrea la posibilidad real de confundir los escenarios de los sueños con la realidad, lo que hace dubitable la posibilidad de cualquier teoría del conocimiento.

PALABRAS CLAVE: Borges, problemas filosóficos, inconsistencias, determinismo, escepticismo.

\section{ABSTRACT}

The next article tries to show how the arguments of some Borges' tales follow the structure of the philosophical problems. The philosophical problems are described as some inconsistencies in the patterns of beliefs that provide a basic image about the way of being of nature and men. "Las tres versiones de Judas" and "Las ruinas circulars", from the book "Ficciones", recreate the philosophical problems of determinism and skepticism, respectively. The first one shows that we can't have a consistent image of our self-determination capacity, when we assume that both, history and natural behavior are not the result of a consecutive performance of cravings phenomena; the second one, recreate the real possibility of confusing the dreams scenario with reality, which becomes unsteady any knowledge theory.

Key words: Borges, the philosophical problems, inconsistencies, determinism, skepticism.

\section{INTRODUCCIÓN}

Cuando se le preguntaba a Jorge Luis Borges por la influencia que recibió de su padre en la formación como escritor, Borges decía que de él nunca recibió una sola recomendación literaria, pero, gracias a él, aprendió cuando sólo era un niño, los problemas esenciales de la filosofía. Resaltaba de su padre que nunca hubiese utilizado un sólo nombre propio, una fecha o un libro de filosofía para explicarle los problemas de la filosofía. Ejemplos u objetos comunes: una mandarina, una partida de ajedrez, le eran suficientes, al profesor de psicología, para llevar a su hijo a los laberintos y aporías de Zenon de Elea, George Berkeley y Arthur Schopenhauer. Y luego, cuando Borges ya puede leer con buen juicio libros de filosofía, El mundo como voluntad y representación de Schopenhauer, Los fragmentos de Heráclito, a Platón y a Berkeley, Borges se da cuenta que la comprensión de los problemas de la filosofía fueron, gracias a su padre, sólo un juego, un juego de sobremesa.

Mi propósito es describir la capacidad que tiene Jorge Luis Borges para recrear, en sus cuentos, problemas filosóficos. Es Borges uno de esos escritores que difuminan las fronteras que demarcan a la filosofía de la literatura, haciendo que la literatura se pasee por la filosofía, y que algunos problemas fundamentales de la filosofía se presenten verosímiles y llanos en el lenguaje público de la literatura. Así, sus cuentos no sólo son ricos e insuperables en prosa fantástica y elocuente, también son fecundos en la recreación de las confusiones y contradicciones de nuestra concepción más básica del mundo -tema central de la filosofía-, que permanece oculto, casi siempre, a nuestras maneras simples y rutinarias de pensar, pero que con su literatura desvela y hace fácilmente descifrables.

\footnotetext{
${ }^{1}$ Las ideas que este artículo analiza forman parte de algunos de los temas de la línea de investigación en Filosofía de la Acción de la Universidad del Quindío. Se expuso la tesis principal en el homenaje que el programa de filosofía de la Universidad del Quindío dio a Jorge Luis Borges en su natalicio. En el participaron los profesores Olga Gualteros, Álvaro Cano, Jairo Urrea y Juan Manuel Acevedo. Sea esta la oportunidad para agradecerles su participación a este evento.
}

Rev. Invest. Univ. Quindío (20): 66 - 71. Armenia - Colombia 
La cercanía que encuentro entre Borges y la filosofía, y sobre todo a la que me referiré, es de contenido y no de forma. Es muy claro que su estilo de escritura no es filosófico. Si bien es admirable su capacidad de síntesis, su compromiso con la elección precisa de las palabras, su exactitud y compenetración con cada uno de los vocablos que configuran sus ensayos, conferencias o cuentos, cierta desconfianza y desdeño al razonamiento calculador, se le hace ineludible para la creación de cada uno de sus escenarios colmados de fantasía; hasta para sus más sobrios y terrenales productos, como eran los de Borges Oral, le era inevitable la prodigalidad de su imaginación. Es justamente la extrema liberalidad del pensamiento borgiano, que es una virtud en la creación literaria pero un desenfreno en la filosofía, lo que hizo de él un escritor de literatura, y no de filosofía. Vale la pena mencionar que Borges, como Schopenhauer, al que Borges le debe la lengua alemana pues la aprendió para poder leerlo, pensaba que la claridad es la cortesía del filósofo, por lo cual, y siguiendo el espíritu de los buenos maestros de filosofía, desdeñaba el lenguaje barroco, la escritura en donde brillan y deslumbran las palabras y no las ideas.

No obstante, su cercanía con la filosofía está en lo sustancial de esta, en sus preguntas esenciales y no en la escritura filosófica. Así que la tentativa de asumir a Borges como un filósofo cuando leemos los ensayos de Borges Oral, por ejemplo, o cuando con arrebato filosófico interpretamos algunos de sus cuentos, es demasiado entusiasta. Aunque veremos que es clara la capacidad que tiene el escritor argentino de convertir en argumentos de cuentos, cuentos cortos, lo que filósofos en sus extensos sistemas y lenguaje técnico intentan explicar, como lo son los problemas que configuran el núcleo de la filosofía.

Para mostrar esta admirable capacidad de Borges, explicaré cómo podemos entender los problemas de la filosofía, cuáles son las características de éstos, y cómo, lo que para los filósofos son descripciones racionales y largas cadenas de inferencias conceptuales, en el universo borgiano son relatos imaginarios y hasta verosímiles, protagonizados por seres que cobran realidad en los sueños y que son inmunes al fuego, que festejan las tragedias de sus destinos, que miden sus días en el río de Heráclito o que, simplemente, son un hombre pero todos los hombres a la vez.

\section{Los Problemas Filosóficos}

Uno de los propósitos esenciales de la filosofía es ofrecer una imagen racional de nuestra comprensión del mundo. Siendo nuestro pensamiento conceptual la manera más depurada y singular de representación de los estados de cosas del mundo, los filósofos han buscado explicar las relaciones conceptuales para esclarecer las maneras como las personas concebimos y nos concebimos en él ${ }^{2}$. Así, un problema filosófico aparece cuando se advierte una inconsistencia en el núcleo de las creencias básicas o conceptos con los que habitualmente representamos el mundo. Podemos asumir a los problemas filosóficos como el resultado de hallar incoherencias en la base de nuestro pensamiento. Por ejemplo, creer que "dios es un ser perfecto y bondadoso que creó todas las cosas", y, a la vez, creer que "el mundo está testado de maldad", analizado con ojos no devotos, nos conducirá sin más a un absurdo, pues la verdad de la primera creencia desmiente la posibilidad de verdad de la segunda: creer que un dios perfecto y bondadoso es el hacedor del mundo, es consistente con que el mundo es un lugar que comparte las cualidades de su creador: perfección y bondad, y no que es un sitio imperfecto y testado de maldad.

Cuando las restricciones que las leyes de la lógica le imponen al pensamiento se ven asaltadas porque identificamos dos verdades que son incoherentes entre sí, tenemos un problema filosófico. Cabe hacer una consideración. Lo que llamamos verdadero o falso son creencias, así, podemos decir que la inconsistencia reside en aceptar dos creencias como verdaderas, cuando necesariamente la verdad de una implica la falsedad de la otra. La verdad de la creencia de que "En el mundo hay maldad e imperfección", implica la falsedad, y no la verdad, de que "el mundo es creado por un ser perfecto y bondadoso". Sin embargo, no hay que olvidar que las creencias, esos paquetes definidos de pensamiento, no son unidades aisladas. Cada creencia existe en tanto pertenezca a un patrón o una red de creencias. El filósofo de la mente y del lenguaje Donald Davidson dice:
Las creencias son identificadas y descritas solamente dentro de patrones densos de creencias. Puedo creer que una nube está pasando delante del sol, pero sólo porque creo que existe un sol, que las nubes están hechas de vapor de agua, que el agua puede existir en forma líquida y gaseosa, y así sucesivamente. No se requiere una lista particular [el subrayado es mío] de creencias adicionales para dar sustancia a mi creencia de que la nube está pasando delante del sol, pero algún conjunto apropiado de creencias relacionadas debe estar presente (Davidson, 1990: 168).

Así, las incoherencias que constituyen los problemas filosóficos se dan, no exclusivamente con respecto al valor de verdad de dos creencias en especial, sino con respecto a dos conjuntos de creencias, o dos redes de creencias, esto porque las creencias son y se sostienen en enlaces de creencias. No obstante, en la intención de aclarar un problema filosófico metódicamente, es útil asumirlo desde dos creencias o dos enunciados que describan las creencias en conflicto.

Volvamos sobre el asunto de la inconsistencia, ahora, entre redes de creencias, para entender lo que se quiere describir sobre los problemas filosóficos. Miremos el caso de los refranes. Los refranes recogen y reflejan conjuntos de

\footnotetext{
${ }^{2}$ Parafraseado a Kant, nuestra experiencia si no está ordenada en un sistema conceptual sería ciega, sería humanamente incomprensible. Realmente los hombres no podríamos ni siquiera pensar en la misma experiencia, ni mucho menos en una imagen del modo de ser de las cosas del mundo, pues dicha imagen sólo es posible en tanto se estructure y configure en nuestros sistemas conceptuales.
} 
creencias de las personas que los predican. Ellos son, como se dice, conocimiento popular. Pero también son una buena muestra de la propensión humana por aceptar conjuntos de creencias inconsistentes entre sí. Sin necesidad de hacer el listado particular de creencias que se trenzan en un refrán, miremos la inconsistencia típica que se da entre dos refranes, $y$, supongamos, entonces, la inconsistencia que se daría realmente en la cadena de creencias que soportan a cada uno. "Las apariencias engañan", si esto es verdadero, todas las creencias que el refrán arrastra también deben ser verdaderas. Pero cuando contrastamos este refrán, con otro igualmente muy popular, podemos detectar una inconsistencia: "la cara es el espejo del alma". La verdad del primer refrán implica la falsedad del segundo y viceversa. Así, no es posible que sean verdaderas al mismo tiempo las expresiones: "Ias apariencias engañan" y "la cara es el espejo del alma". Tenemos, entonces, que las personas que aceptan, a la par, la sabiduría popular que se expresa en ambos refranes, están presas de una inconsistencia racional: sus mentes infringen una de las exigencias de la racionalidad, como es la de no aceptar la contradicción.

Como atenuante a esta propensión humana hacia la contradicción, hay que decir, que este tipo de contradicciones son tácitas, pues regularmente nuestra relación con las creencias de esta clase es de tipo práctico y no reflexivo. Nuestra capacidad de tener creencias de segundo orden, es decir, creencias sobre creencias, es la que advierte sobre las contradicciones; pero cuando nuestras creencias sólo están dirigidas a la ejecución o evaluación de nuestras acciones diarias, difícilmente nos percatamos de nuestras incoherencias mentales.

Como anteriormente se mencionó, la filosofía, en su aspiración a presentar una imagen coherente de nuestra comprensión del mundo, va en busca de las inconsistencias o contradicciones entre los núcleos de nuestras creencias. Básicamente, dos son las maneras que siguen los filósofos para corregirlas. La primera, mostrando que tales inconsistencias se deben, eventualmente, a nuestra mala comprensión de los presupuestos que están en la base de las redes de creencias. Muestran que hemos andado 'algo ligero' en los fundamentos de un patrón de creencias y que, con algo de cautela, lo que antes se revelaba como una contradicción es un error de interpretación. La segunda, consiste en mostrar que es el incorrecto uso de las palabras el que provoca la contradicción: en tanto nuestras creencias se expresan a través del lenguaje, la vaguedad, que es su sombra, induce constantemente hacia ella. El modo usual y útil para resolverlas estas contradicciones es intentando dar una definición precisa de las palabras.

No obstante, en filosofía hay una serie de inconsistencias entre importantes núcleos de creencias que se resisten a ser resueltos por el camino de la aclaración de los presupuestos o bien por el del uso exacto y meticuloso de las palabras. Son estos problemas los que aparecen en cada época de la filosofía, rebanando los cerebros de los más ilustres filósofos cuando buscan plantearlos, esclarecerlos y resolverlos, y que, literatos como Jorge Luis Borges plantean y esclarecen en sus cortos cuentos; los que después de haber sido leídos dan la capacidad de relatar dichos problemas como charlas de sobremesa. Dos son los que en esta exposición voy a presentar y a recrear desde dos cuentos de Borges y algunos versos de sus poemas: el problema del determinismo desde "Las tres versiones de Judas" y el problema del escepticismo desde la mirada de "Las ruinas circulares".

\section{Libertada, determinismo en "Las tres versiones de Judas"}

"El libre albedrio es una ilusión necesaria". Jorge Luis Borges

\section{Ajedrez II \\ Tenue rey, sesgo alfil, encarnizada \\ Reina, torre directa y peón ladino. \\ Sobre lo negro y blanco del camino \\ Buscan y libran su batalla armada. \\ No saben que la mano señalada \\ Del jugador gobierna su destino, \\ No saben que un rigor adamantino \\ Sujeta su albedrío y su jornada.}

También el jugador es prisionero

(La sentencia es de Omar) de otro tablero

De negras noches y de blancos días.

Dios mueve al jugador y éste, la pieza.

¿Qué dios detrás de Dios la trama empieza

De polvo y tiempo y sueño y agonía?

\section{Elhacedor(1960)}

Los dos patrones de creencias inconsistentes que constituyen el problema filosófico del determinismo son nuestra creencia en "la causalidad universal" y nuestra creencia en "los actos de la volición". Si creemos en la causalidad universal, debemos aceptar como falso que podemos elegir el curso de nuestras acciones; si aceptamos que es verdadera la creencia de que elegimos lo que haremos, debemos negar la causalidad universal. Para ponerlo en otros términos, creemos que toda cosa que existe, todo suceso que se da en el mundo, ha de haber sido causado por otro que existía con anterioridad. Las fichas del ajedrez existen en tanto existan otras cosas previas que provocaron su existencia. El nogal, el artesano y sus herramientas, en conjunción, permiten la existencia del Caballo, el Peón y la Reina; y los movimientos de estos, citando a Borges: "sobre lo negro y lo blanco de camino" a su vez, sólo son posibles gracias a la existencia previa del jugador que causa su desplazamiento. Así, creemos que todo cuanto ocurre ha de tener una causa, pues de la nada, de la no existencia, no se sigue la existencia. Pero a su vez, sin embargo, creemos en nuestra voluntad o en nuestra capacidad de elección: el jugador de Ajedrez elige hacer la jugada arriesgada o mover la ficha con prudencia. Pensamos que somos dueños de nuestro futuro y que podemos construirlo siguiendo nuestro arbitrio. Elegimos nuestra profesión, nuestras compañías, lo que comemos, lo que nos ponemos. Creemos que somos libres de ser lo que somos y con ello, de dejar de serlo. Como diría María Kodama, la viuda de Borges, al referirse a los actos volitivos del poeta: "Borges llevó la libertad de ser uno mismo hasta sus últimas consecuencias".

No obstante, cuando reparamos en las bases de ambas redes 
de creencias, nos encontramos con una inconsistencia. Si creemos en la libertad, no podemos creer en la causalidad; si creemos en la causalidad, es falsa nuestra libertad. Borges, como podemos leer en su poema, tiende a creer en una inevitable causalidad rigiendo, sin intersticios, la totalidad del universo. Es uno de sus temas frecuentes. Algunos de sus cuentos ubican su nudo sobre la tensión que surge de la incongruencia entre ambas redes, cruce que lo orienta hacia terrenos de la filosofía. Y el desenlace, que no es otra cosa que la ilustración de su posición filosófica, es el determinismo. La creencia en la causalidad universal se le impone sobre la creencia en la libertad:

Dios mueve al jugador y éste, la pieza.

¿Qué dios detrás de Dios la trama empieza

De polvo y tiempo y sueño y agonía?

0 , como lo expresa en el verso 39 de sus fragmentos de un evangelio apócrifo: "la puerta es la que elige, no el hombre".

En su cuento "Las tres versiones de Judas" (Ficciones, 1944), Borges pone en tela de juicio nuestra imagen coherente del mundo con respecto a los pasajes más canónicos del cristianismo. Nos revela una inconsistencia filosófica. Instalado en los nodos de nuestras creencias con respecto a la causalidad universal, nos arrastra hacia la necesidad lógica de asumir a Judas Iscariote como la genuina reencarnación humana de Dios. Es decir, si creemos que todo tiene una causa, entonces nuestra imagen sobre Judas Iscariote, ha sido históricamente desafortunada; es una de esas inconsistencias nacidas por nuestras maneras apresuradas de aceptar y asumir nuestras creencias. Citando a Borges: "No puede haber un hecho casual en el más preciso acontecimiento de la historia del mundo". La traición de Judas es un hecho tan necesario para los propósitos de Dios, que una pasión tan fugaz como el deseo por unas monedas de oro, es apenas ridícula para explicar su puesto en la historia del hombre. "No una, todas las cosas que la tradición atribuye a Judas Iscariote son falsas".

Sí creemos que tenemos libertad en la elección de nuestras decisiones, estaríamos obligados a creer que toda la obra de la redención divida, dependía del arbitrio de un solo hombre, uno que se dejaba seducir fácilmente por la ridiculez de unas monedas de oro. No sería propia de la sensatez de Dios guardar su obra en tan miserable hombre. Por eso, en el Judas de Borges, Judas es el verdadero asceta. Escribe en su cuento "Las tres versiones de Judas":

El asceta, para mayor gloria de Dios, envilece y mortifica la carne; Judas hizo lo propio con el espíritu. Renunció al honor, al bien, a la paz, al reino de los cielos, como otros, menos heroicamente, al placer. Premeditó con lucidez terrible sus culpas. En el adulterio suelen participar la ternura y la abnegación; en el homicidio, el coraje; en las profanaciones y blasfemia, cierto fulgor satánico. Judas eligió aquellas culpas no visitadas por ninguna virtud: el abuso de confianza. (Juan 12: 6) y la delación. Obró con gigantesca humildad, se creyó indigno de ser bueno (Borges, 1984: 151).
Así, la inconsistencia filosófica que nos revela Borges a través de su cuento, la podemos resumir en este dilema: creemos que somos libres, y por eso condenamos históricamente la traición de Judas; sin embargo, creemos que Judas con su traición permitió toda la obra de la redención cristiana, entonces, no podemos creer en la libertad, porque el plan divino de dios no puede depender de la decisión de un hombre tan miserable; así que Judas no es realmente un traidor sino un amanuense de dios. Judas Iscariote, en tanto hombre, representa a todos lo hombres, parafraseando a Borges, es un hombres que es todos los hombres y a la inconsistencia con respecto a nuestras creencias en la libertad. Como ya dijimos, Borges toma partida filosófica por el determinismo. Judas Iscariote es la verdadera reencarnación de dios, porque a diferencia de Jesús, que padeció algunas horas en la cruz, el decidió el castigo eterno. Judas se negó el paraíso para permitir el plan de redención de dios con los hombres

Dios totalmente se hizo hombre hasta la infamia, hombre hasta la reprobación y el abismo. Para salvarnos, pudo elegir cualquiera de los destinos de la trama de la perpleja red de la historia; pudo ser Alejandro o Pitágoras o Rurik o Jesús; eligió un ínfimo destino: fue Judas (Ibíd.: 153).

\section{Conocimiento y escepticismo en Las Ruinas Circulares}

\section{Descartes}

Soy el único hombre en la tierra y acaso no hay tierra ni hombre.

Acaso un dios me engaña.

Acaso un dios me ha condenado al tiempo, esa larga ilusión.

Sueño la luna y sueño mis ojos que perciben la luna. He soñado a Cartago y a las legiones que desolaron a Cartago.

He soñado a Lucano.

He soñado la colina del Gólgota y las cruces de Roma. He soñado la geometría.

He soñado el punto, la línea, el plano y el volumen. He soñado el amarillo, el azul y el rojo.

He soñado mi enfermiza niñez.

He soñado los mapas y los reinos y aquel duelo en el alba.

He soñado el inconcebible dolor.

He soñado mi espada.

He soñado a Elisabeth de Bohemia.

He soñado la duda y la certidumbre.

He soñado el día de ayer.

Quizá no tuve ayer, quizá no he nacido.

Acaso sueño haber soñado.

Siento un poco de frío, un poco de miedo.

Sobre el Danubio está la noche.

Seguiré soñando a Descartes y a la fe de sus padres. La cifra (1981)

El escepticismo, otro de los clásico e irresolubles problemas filosóficos, revela la ya descrita estructura lógica de los problemas filosóficos, y es un tema también frecuente en los 
versos y prosa de Borges. Descartes, con su célebre argumento del sueño, llevó hasta el límite la posibilidad de la dubitación filosófica. Sobre la base de lo que son los problemas filosófico podemos reconstruir el escepticismo así: por un lado tenemos una creencia que consideramos incontrovertible, y a la que nos sentimos incapaces de renunciar, pero, por otro lado, tenemos otra creencia inconsistente y contradictoria con la primera, e igualmente irrenunciable. Creemos $\boldsymbol{p}$ y a la vez creemos $\boldsymbol{q}$, pero una vez que hemos analizado críticamente a $\boldsymbol{p}$ y a $\boldsymbol{q}$ caemos en la cuenta de que creer en $\boldsymbol{p}$ hace imposible a $\boldsymbol{q}$; o creer en $\boldsymbol{q}$ hace imposible a $\boldsymbol{p}$. Así, creemos que podemos tener conocimiento del mundo externo. A esto lo podemos llamar $\boldsymbol{p}$. Por otra parte, reconocemos que es posible confundir nuestras experiencias reales con las que vivimos durante los sueños. A esto lo podemos llamar $\boldsymbol{q}$. Pero para saber algo del mundo externo tenemos que poder distinguir claramente los sueños de la realidad. Así que, ¿cómo podemos saber que $\boldsymbol{p}$, si es posible $\boldsymbol{q}$ ?; si $\boldsymbol{q}$ es posible, como parece serlo, ¿no es verdadera $\boldsymbol{p}$ ?

El tema de la dificultad de distinguir entre sueño y realidad es recurrente en Borges, y en esto, el escritor argentino no es muy original, pues Pedro Calderón de la Barca en su novela $L a$ vida es sueño, muchos antes ya lo había recreado. Igualmente, Sócrates en las conversaciones que sostiene con el avezado Teetetes sobre lo que es el conocimiento, señala la dificultad que surge cuando, con rigor filosófico, inténtanos distinguir los sueños de la vigilia. Al respecto el mismo Blas Pascal, en su libro Pensamientos, igualmente lo había considerado. Dice:

Si soñáramos todas las noches con la misma cosa, nos afectaría tanto como los objetos que vemos todos los días. Y si un artesano estuviera seguro de soñar todas las noches, durante doce horas, que es rey, creo que sería casi tan feliz como un rey que soñara durante todas las noches, durante doce horas, que es artesano (Pascal, 1981: 70).

La inconsistencia que revela el escepticismo se ubica en nuestra creencia de la existencia verdadera de los escenarios que surgen durante los sueños cuando estamos dormidos, y la imposibilidad de tener un criterio certero que nos permita distinguirlos plenamente de lo que acontece en la realidad. En Borges esto se convierte en literatura fantástica. En "Las ruinas circulares" del libro Ficciones, un hombre desembarca en las ruinas de un templo sagrado consumido por el fuego. Su único propósito era: "Quería soñar un hombre: quería soñarlo con integridad minuciosa e imponerlo a la realidad" (Op. Cit.: 52). Lentamente su empresa fue llegando a buen término. Día tras día sus sueños fueron configurando la forma humana requerida para hacer un hombre. Un dios le concedió que su creación onírica dejase la dependencia de su imaginación para habitar el mundo externo. La única singularidad del hombre creado por los sueños era su inmunidad al fuego. "Todas las criaturas, excepto el Fuego mismo y el soñador, lo pensaran un hombre de carne y hueso" (Ibíd.: 55). El soñador se da cuenta que su creación efectivamente se volvió real, cuando escuchó que en un templo existía un gran mago que controlaba los poderes del fuego, y que éste nunca lo consumía. Lo vertiginoso del cuento está en el final, cuando el soñador, el creador del golem inmune al fuego, ve como el templo que convirtió en su morada fue de nuevo abrazado por el fuego, y:

Por un instante pensó en refugiarse en las aguas; pero luego comprendió que la muerte venía a coronar su vejez y a absolverlo de sus trabajos. Caminó contra los jirones de fuego. Estos no mordieron su carne, estos lo acariciaron y lo inundaron sin calor y sin combustión. Con alivio, con humillación, con terror, comprendió que él también era una apariencia, que otro estaba soñándolo (Ibíd.: 58).

De nuevo la maestría de Borges para recrearnos, sencilla y verosímilmente, los problemas filosóficos se hace evidente. Él soñador en un comienzo del cuento representa los estados de vigilia. Su dominio y capacidad de distinguir entre lo real y lo onírico se muestra en su decisión de crear, él, un ser real, otro ser imaginario, pero con visos de realidad; uno hecho de la materia de los sueños. Pero el soñador, también termina siendo un sueño. Entonces, ¿dónde trazar la frontera entre los sueños y la realidad?

Hoy este problema filosófico es presentado bajo las imágenes de "cerebros en cubetas" o el argumento Matrix, y cada imagen se desenvuelve en filosofía a partir de su formalización lógica. Con Borges, desde la lectura de uno de sus cuentos, la tensión e inconsistencia entre creencias, necesarias para entender el problema filosófico, se hace simple y sensible. En la brevedad de un cuento recoge la curiosidad de vértigo que apasiona al estudioso de la filosofía, y que se alcanza después de rigurosas y arduas lecturas filosóficas.

Como todo genio, Borges amplio las fronteras de su disciplina. Creo que Vladímir Propp nunca se imaginó que en la morfología de los cuentos era posible también configurar extraordinarias narraciones que tienen, como únicos argumentos, las inconsistencias de nuestras creencias básicas, y que dentro de nuestra imagen racional, la filosofía desvela y la literatura borgiana presenta como juego de sobremesa. 


\section{BIBLIOGRAFÍA}

Aristóteles. (1979). El Organon. México, D. F.: Porrúa.

Borges, Jorge Luis. (1984). Ficciones. Buenos Aires: Oveja Negra.

. (1985). Borges oral. Barcelona: Bruguera.

(2007). Obras completas. Bogotá: Emecé.

Berkeley, George. (1939). Tratado sobre los principios del conocimiento humano. Buenos Aires: Losada.

Copi, Irving. (1971). Introducción a la lógica. Buenos Aire: Eudeba.

Cornman, J., Pappas, G., Lehrer, K. (1980). Problemas y argumentos filosóficos. México: Universidad nacional Autónoma de México.

Dancy, Jonathan. (1993). Introducción a la epistemología contemporánea. Madrid: Tecnos.

Descartes. (1960). Meditaciones metafísicas. Buenos Aires: Charcas.

Davidson, Donald. (1990). De la verdad y de la interpretación. Barcelona: Gedisa.

Muguerza, J. (1974). La concepción analítica de la filosofía. Madrid: Alianza.

Kant, Emmanuel. (1995). Crítica de la razón pura. Madrid: Alfaguara.

Pascal. (1981). Pensamientos. Madrid: Espasa Calpe.

Posada, Gregorio. (2007). La definición tripartita del conocimiento, una introducción a la epistemología. Manizales:

Universidad de Caldas.

Schopenhauer, Arthur. (2005). El mundo como voluntad y representación. Madrid: Fondo de cultura económica.

Russell, Bertrand. (1970). Los problemas de la filosofía. Barcelona: Labor. 